\title{
Chloräthyl mit Zusatz von Eau de Cologne zur Narkose.
}

Die von Geh.-Rat P. Colme rs (München) in Nr. 11 S. 455 als besonders zuverlässiges und gutes Geruchskorrigens zum Chloräthyl neu angegebene Eau de Cologne ist hereits im Jahre 1924 von

D r e e smann empfohlen und wird auf mein Anraten hin bereits seit 1926 von der Chemischen Fabrik G. Hennig in Berlin in gebrauchsfertiger Packung in den Handel gebracht, allerdings mit dem Unterschiede, daB Colmers eine bestimmte Art der Eau de Cologne, nämlich die von Johann Maria Farina. Köln, gegenüber dem Jülichplatz, als Zusatz gewählt hat. Dr. E. Go hr ba nd t (Berlin). 